\title{
Polymerization of Benzyl Vinyl Ether with a Ziegler Catalyst and Reaction of Poly(Benzyl Vinyl Ether) with $\mathbf{T i C l}_{4}$
}

\author{
Heimei Yuki and Koichi Hatada \\ Department of Chemistry, Faculty of Engineering Science, Osaka University, \\ Toyonaka, Osaka, Japan.
}

Shunsuke Murahashi and the late Koichi Hibino

Department of Polymer Science, Faculty of Science, Osaka University, Toyonaka, Osaka, Japan.

(Received July 16, 1969)

\begin{abstract}
The polymerization of benzyl vinyl ether (BVE) was investigated in toluene by $\mathrm{Et}_{3} \mathrm{Al}-\mathrm{TiCl}_{4}$ catalyst. When the catalyst preparation and the monomer addition were carried out at $0^{\circ} \mathrm{C}$ and the reaction mixture was brought to $60^{\circ} \mathrm{C}$, an insoluble polymeric product was obtained together with poly(benzyl vinyl ether) (PBVE). This insoluble product was revealed to be a polymer composed of BVE and vinyl alcohol units complexed with titanium compound. This was formed by the reaction of PBVE and $\mathrm{TiCl}_{4}$ in the catalyst system and the subsequent hydrolysis of the reaction product. Poly(vinyl alcohol) (PVA) complexed with a titanium compound was obtained by the reaction of $\mathrm{PBVE}$ and $\mathrm{TiCl}_{4}$ in toluene at room temperature. When the molar ratio of $\mathrm{TiCl}_{4}$ to PBVE was above 0.3 , PBVE was completely debenzylated and became insoluble by being complexed with a titanium compound. The composition of this product was roughly estimated to be $\left[-\left\{-\mathrm{CH}_{2}-\mathrm{CH}(\mathrm{OH})-\right\}_{6^{-}} \mathrm{TiCl}(\mathrm{OH})_{3}\right]_{n}$. The complexed PVA was soluble only in hydrochloric acid and could be converted to free PVA by reprecipitation from a solution containing acetylacetone.

KEY WORDS Benzyl Vinyl Ether / Poly(Benzyl Vinyl Ether)/ $\mathrm{Et}_{3} \mathrm{Al}-\mathrm{TiCl}_{4} /$ Reaction / Complexation /
\end{abstract}

Stereospecific polymerizations of vinyl ether with Ziegler-type catalysts have been reported by several authors. ${ }^{1}$ Vandenberg $^{2}$ has reported that a crystalline poly(benzyl vinyl ether) (PBVE) was obtained by the polymerization of benzyl vinyl ether (BVE) using Ziegler-type catalysts. They reported that the polymer had a high melting point and was insoluble in acetone and ether. On the other hand, an isotactic poly(vinyl alcohol) (PVA) has been obtained by the debenzylation of an isotactic PBVE obtained by a $\mathrm{BF}_{3} \cdot \mathrm{OEt}_{2}$ catalyst at low temperature. ${ }^{3}$

The present authors have studied the polymerization of benzyl vinyl ether (BVE) by triethylaluminum-titanium chloride and, in connection with this, the reaction of PBVE and titanium tetrachloride. No crystalline PBVE was produced by the polymerization, but the polymer obtained was one partly debenzylated and com- plexed with a titanium compound. It was found that the debenzylation occurred by the reaction of $\mathrm{PBVE}$ and $\mathrm{TiCl}_{4}$. In this paper the results of these investigations are reported.

\section{EXPERIMENTALS}

\section{Reagents}

Benzyl vinyl ether was prepared from benzyl alcohol and acetylene by the catalysis of potassium hydroxide according to Reppe's method. ${ }^{4}$ The monomer obtained was treated successively with sodium, calcium hydride and lithium aluminum hydride under dry nitrogen with stirring at $60^{\circ} \mathrm{C}$, and then distilled under reduced pressure: bp $59.1^{\circ} \mathrm{C}(5.4 \mathrm{~mm}) ; n_{\mathrm{D}}^{20} 1.5162$ (lit. $\left.{ }^{4} 1.5160\right)$. The purified BVE was sealed in ampoules under dry nitrogen and stored at $-20^{\circ} \mathrm{C}$.

$n$-Butyl benzyl ether ${ }^{5}$ was prepared by the reac- 
tion of benzyl chloride and sodium $n$-butoxide in butanol: bp $106-107^{\circ} \mathrm{C}(17 \mathrm{~mm}) ; n_{\mathrm{D}}^{20} 1.4868$.

Toluene and $n$-hexane were purified by the usual methods and stored over metallic sodium.

The triethyl aluminum used $\left(\mathrm{Et}_{3} \mathrm{Al}\right)$ was a commercial product of the Ethyl Corporation and was used as a $30 \%$ solution in $n$-heptane without purification.

Titanium tetrachloride was also of commercial source and was used as a solution in $n$-heptane without further purification.

Boron trifluoride etherate $\left(\mathrm{BF}_{3} \cdot \mathrm{OEt}_{2}\right)$ was purified by distillation under reduced nitrogen pressure and was used as a toluene solution.

\section{Polymerization of BVE by a Ziegler Catalyst}

An ampoule equipped with a three-way stopcock was flushed with dry nitrogen and $20 \mathrm{~m} l$ of toluene and $1.32 \mathrm{mmol}$ of $\mathrm{Et}_{3} \mathrm{Al}$ were introduced with hypodermic syringes. To the solution $1.32 \mathrm{mmol}$ of $\mathrm{TiCl}_{4}$ was slowly added dropwise along the wall of the vessel under dry nitrogen. After ten minutes $3 \mathrm{~g}$ of BVE was added and the polymerization was carried out at a desired temperature. Then the reaction mixture was cooled to room temperature and poured into $500 \mathrm{~m} l$ of methanol containing $0.3 \mathrm{~m} l$ of concentrated hydrochloric acid. After standing overnight, the polymer precipitated was collected, washed with methanol and dried in vacuo at room temperature. The polymer obtained was fractionated by extraction with boiling acetone into soluble (Polymer A) and insoluble (Polymer B) parts.

\section{Polymerization of $\mathrm{BVE}$ by $\mathrm{BF}_{3} \cdot \mathrm{OEt}_{2}{ }^{6}$}

The ampoule as mentioned above was flushed with dry nitrogen and $75 \mathrm{ml}$ of toluene, $25 \mathrm{ml}$ of $n$-hexane and $9.7 \mathrm{~g}$ of BVE were introduced. The mixture was cooled to $-78^{\circ} \mathrm{C}$ by a Dry Iceacetone bath and then $1 \mathrm{~m} l$ of precooled $5-\%$ solution of $\mathrm{BF}_{3} \cdot \mathrm{OEt}_{2}$ in toluene was added. After 2.5 hours the polymerization was terminated by the addition of $5 \mathrm{ml}$ of ammoniac methanol and then the mixture was poured into $300 \mathrm{~m} l$ of methanol. After standing overnight, the precipitated polymer was collected, washed with methanol and dried in vacuo at room temperature: yield $8.9 \mathrm{~g},[\eta] 3.00 \mathrm{~d} l / \mathrm{g}$ (in toluene at $30.0^{\circ} \mathrm{C}$ ).

\section{Reaction of $\mathrm{PBVE}$ and $\mathrm{TiCl}_{4}$}

The polymer was dissolved in toluene at a given concentration $\left(3.8 \times 10^{-2} \mathrm{~mol} / \mathrm{l}\right.$ based on the monomer unit). Titanium tetrachloride was also dissolved in toluene at the same concentration as that of the polymer solution. The two solutions were mixed in various proportions at $60^{\circ} \mathrm{C}$, the total volume being $40 \mathrm{ml}$, and the reaction was carried out for $4 \mathrm{hr}$ at that temperature. Then the precipitate formed (Polymer D) was quickly separated by filtration, washed successively with $5 \mathrm{ml}$ of toluene and $20 \mathrm{ml}$ of methanol containing about $5 \%$ of water and dried in vacuo. The filtrate was poured into $500 \mathrm{ml}$ of methanol to precipitate the polymer remaining in the solution. After standing overnight the precipitated polymer (Polymer C) was collected, washed with methanol and dried in vacuo at room temperature.

\section{RESULTS}

\section{Polymerization of BVE by a Ziegler Catalyst}

The polymerization of $\mathrm{BVE}$ by the $\mathrm{Et}_{3} \mathrm{Al}-\mathrm{TiCl}_{4}$ catalyst was carried out by varying the temperature at the catalyst preparation and at the monomer addition. The results are shown in Table I. The rate of polymerization was extremely low at $-78^{\circ} \mathrm{C}$. Such a very low activity of the Ziegler catalyst at low temperature is generally observed in the polymerization of olefin by this catalyst. At above $0^{\circ} \mathrm{C}$ the polymerization proceeded smoothly and gave the polymer in good yield. Usually the polymers (Polymer A) obtained were soluble in acetone as well as in benzene and toluene but insoluble in methanol, ethanol and water. These were glassy solids in yellow color and liquefied when warmed below $50^{\circ} \mathrm{C}$. Their infrared spectra were identical to that of PBVE obtained by the $\mathrm{BF}_{3} \cdot \mathrm{OEt}_{2}$ catalyst. The intrinsic viscosities of the polymer solutions were in a range of $0.1-0.2$

On the other hand, the formation of an insoluble polymer was observed when the monomer was added to the catalyst prepared at room temperature and then the mixture was heated to $60^{\circ} \mathrm{C}$. In appearance the reaction mixture was homogeneous during the polymerization as if the polymer formed was wholly dissolved in the reaction medium. However, after the precipitation of 
Polymerization of Benzyl Vinyl Ether with Ziegler Catalyst

Table I. Polymerization of BVE by a Ziegler catalysta

\begin{tabular}{|c|c|c|c|c|c|}
\hline \multirow{2}{*}{ Catalyst } & \multirow{2}{*}{$\begin{array}{c}\text { Temp. at } \\
\text { monomer } \\
\text { addition }\left({ }^{\circ} \mathrm{C}\right)\end{array}$} & \multicolumn{2}{|c|}{ Polymerization } & \multicolumn{2}{|c|}{ Polymer yield (\%) } \\
\hline & & Temp. $\left({ }^{\circ} \mathrm{C}\right)$ & Time $(\mathrm{hr})$ & Total & Polymer B \\
\hline \multirow{3}{*}{$\mathrm{Et}_{3} \mathrm{Al}-\mathrm{TiCl}_{4}{ }^{\mathrm{b}}$} & -78 & -78 & 28 & 21 & 0.5 \\
\hline & 0 & 0 & 4 & 83 & Trace \\
\hline & 0 & 60 & 4 & 72 & $42.6^{e}$ \\
\hline \multirow{2}{*}{$\mathrm{Et}_{3} \mathrm{Al}-\mathrm{TiCl}_{4}{ }^{\mathrm{e}}$} & 25 & 60 & 4 & 84 & Trace \\
\hline & 0 & 60 & 4 & 78 & 0.7 \\
\hline \multirow{2}{*}{$\mathrm{Et}_{3} \mathrm{Al}-\beta-\mathrm{TiCl}_{3} \mathrm{~d}$} & -78 & -78 & 6 & 3 & Trace \\
\hline & 0 & 60 & 4 & 59 & Trace \\
\hline
\end{tabular}

a Monomer, $2.9 \mathrm{~g}$; Solvent (toluene), $20 \mathrm{ml}$; Et ${ }_{3} \mathrm{Al}, 1.32 \mathrm{mmol}$; Ti compound, $1.32 \mathrm{mmol}$.

b Prepared at room temperature.

c Prepared at $110^{\circ} \mathrm{C}$.

d $\beta-\mathrm{TiCl}_{3}$ was prepared by the reaction of $\mathrm{Et}_{3} \mathrm{Al}$ and $\mathrm{TiCl}_{4}(1: 1)$ at $98^{\circ} \mathrm{C}$.

e Elementary analysis of this part [Found: C, 75.2; H, 7.3; ash 3.5. Calcd for $\operatorname{PBVE}\left(\mathrm{C}_{9} \mathrm{H}_{10} \mathrm{O}\right)$ : C, 80.6; H, 7.5.].

the polymer in methanol a part of it became insoluble not only in toluene but also in most of the usual organic solvents. This insoluble fraction (Polymer B) was separated from the soluble one (Polymer A) by fractionation with boiling acetone. Polymer B was elastic and gradually decomposed above $150^{\circ} \mathrm{C}$. Its infrared spectrum was practically identical with that of Polymer A except an absorption at $3500 \mathrm{~cm}^{-1}$. This was completely dissolved in boiling cyclohexanone after being refluxed for several hours. From the solution a soluble polymer was recovered by pouring it into a large amount of methanol. This polymer had almost the same properties as those shown by polymer $\mathrm{A}$, that is, color, softening point, solubility, solution viscosity, and IR spectrum except the band at $3500 \mathrm{~cm}^{-1}$.

The polymerization of $\mathrm{BVE}$ was also carried out using $\mathrm{TiCl}_{4}, \mathrm{Et}_{3} \mathrm{Al}, \mathrm{TiCl}_{3}$, and $\mathrm{Et}_{2} \mathrm{AlCl}$ as catalysts which are supposed to be the components of the Ziegler catalyst. The results are shown in Table II. No polymer was obtained from the $\mathrm{Et}_{3} \mathrm{Al}$ catalyst, but an acetone-soluble polymer was formed by the others. The poly-

Table II. Polymerization of BVE with various catalysts ${ }^{a}$

\begin{tabular}{|c|c|c|c|c|}
\hline \multirow[b]{2}{*}{ Catalyst } & \multicolumn{2}{|c|}{ Polymerization } & \multicolumn{2}{|c|}{ Polymer yield $(\%)$} \\
\hline & $\begin{array}{c}\text { Temp. } \\
\left({ }^{\circ} \mathrm{C}\right)\end{array}$ & $\underset{(\mathrm{hr})}{\operatorname{Time}}$ & Total & $\begin{array}{c}\text { Acetone-insoluble } \\
\text { part }\end{array}$ \\
\hline $\mathrm{TiCl}_{4}$ & -78 & 6 & 42.8 & 0.0 \\
\hline " & -78 & 6 & 27.4 & 0.2 \\
\hline " & 12 & 6 & 76.7 & 1.9 \\
\hline " & 60 & 4 & 59.5 & 15.8 \\
\hline$\beta-\mathrm{TiCl}_{3}$ & -78 & 4 & 4.5 & Trace \\
\hline II & 60 & 4 & 19.2 & 1.1 \\
\hline $\mathrm{Et}_{2} \mathrm{AlCl}$ & -78 & 4 & 2.9 & 0.0 \\
\hline " & 60 & 4 & 76.2 & 0.0 \\
\hline $\mathrm{Et}_{3} \mathrm{Al}$ & -78 & 4 & 0.0 & 0.0 \\
\hline " & 60 & 4 & 0.0 & 0.0 \\
\hline
\end{tabular}

a Monomer, $2.9 \mathrm{~g}$; Solvent (toluene), $20 \mathrm{ml}$; Catalyst, $1.32 \mathrm{mmol}$. 
merization by $\mathrm{TiCl}_{4}$ also gave a small amount of acetone-insoluble polymer, especially at elevated temperatures.

Reaction of PBVE and $\mathrm{TiCl}_{4}$

The reaction of PBVE and $\mathrm{TiCl}_{4}$ was investigated in order to elucidate the formation of insoluble polymer in the polymerization of BVE with the $\mathrm{TiCl}_{4}-\mathrm{AlEt}_{3}$ catalyst. As Polymer A was usually contaminated with inorganic sub- stances originating in the catalyst, the polymer obtained by $\mathrm{BF}_{3} \cdot \mathrm{OEt}_{2}$ was mainly used in the reaction.

The results of the reactions of $\mathrm{TiCl}_{4}$ and PBVE obtained by $\mathrm{BF}_{3} \cdot \mathrm{OEt}_{2}$ are shown in Figure 1 . Similar results were obtained in the reactions of $\mathrm{TiCl}_{4}$ and the acetone-soluble polymer (Polymer A) obtained by a Ziegler catalyst.

When the molar ratio of $\mathrm{TiCl}_{4}$ to PBVE (based

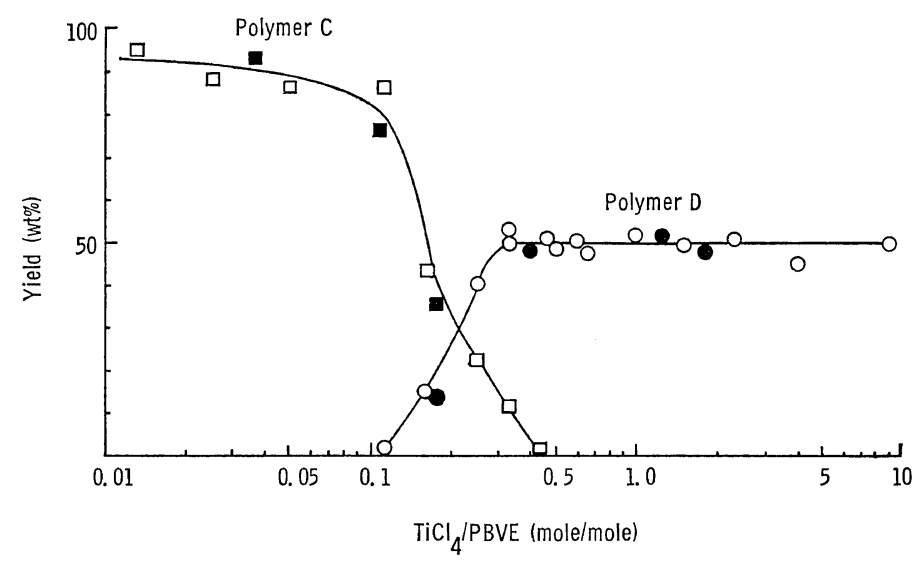

Figure 1. The reaction of $\mathrm{PBVE}$ and $\mathrm{TiCl}_{4}$. Yield of the reaction product $v s$. $\mathrm{TiCl}_{4} / \mathrm{PBVE}$ ratio.

The solid symbols designate the data for the reaction products of Polymer A.

Table III. Elementary analysis and supposed compositions of the reaction products of PBVE and $\mathrm{TiCl}_{4}$

\begin{tabular}{|c|c|c|c|c|c|c|c|c|}
\hline \multirow{2}{*}{ Classification } & \multirow{2}{*}{$\begin{array}{c}\mathrm{TiCl}_{4} / \mathrm{PBVE} \\
(\mathrm{mol} / \mathrm{mol})\end{array}$} & \multicolumn{4}{|c|}{ Elementary analysis (\%) } & \multicolumn{3}{|c|}{$(\mathrm{BVE})_{m}(\mathrm{VA})_{n} \mathrm{TiCl}_{k}(\mathrm{OH})_{4-k_{k}} \mathrm{~b}$} \\
\hline & & $\mathrm{C}$ & $\mathrm{H}$ & $\mathrm{Cl}$ & $\mathrm{Ti}$ & $m$ & $n$ & $k$ \\
\hline \multirow{7}{*}{ Polymer D } & 9.0 & 38.2 & 7.0 & 4.6 & 12.4 & 0.2 & 5.5 & 0.5 \\
\hline & 4.0 & 36.0 & 6.9 & 6.3 & 13.3 & 0.1 & 5.0 & 0.6 \\
\hline & 2.3 & 34.0 & 7.0 & 8.7 & 11.1 & 0 & 5.9 & 1.1 \\
\hline & 1.5 & 31.9 & 6.9 & 10.0 & 11.3 & 0 & 5.5 & 1.2 \\
\hline & 0.6 & 33.5 & 6.9 & 7.8 & 13.0 & 0 & 5.1 & 1.2 \\
\hline & 0.46 & 36.3 & 6.8 & 7.9 & 11.2 & 0 & 6.4 & 1.0 \\
\hline & 0.25 & 60.6 & 6.8 & 3.2 & 7.1 & 3.2 & 2.8 & 0.6 \\
\hline \multirow{4}{*}{ Polymer C } & 0.25 & 63.1 & 7.3 & 3.1 & 4.3 & 4.8 & 7.6 & 1.0 \\
\hline & 0.11 & 75.7 & 7.5 & 0.9 & 1.5 & 21.3 & 4.5 & 0.8 \\
\hline & 0.05 & 77.8 & 7.4 & 0.0 & 1.3 & 26.4 & 0.9 & 0 \\
\hline & 0.013 & 79.3 & 7.5 & 0.0 & 0.7 & 50.1 & 0 & 0 \\
\hline
\end{tabular}

a Based on the monomer unit.

b $\mathrm{BVE}=-\mathrm{CH}_{2}-\mathrm{CH}-$

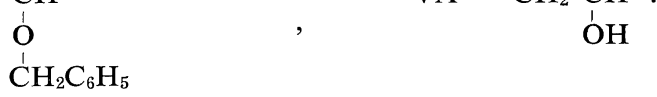

Calcd for $(\mathrm{VA})_{6} \mathrm{TiCl}(\mathrm{OH})_{3}: \mathrm{C}, 33.9 ; \mathrm{H}, 6.5 ; \mathrm{Cl}, 10.0 ; \mathrm{Ti}, 13.5$.

Calcd for BVE: C, 80.6; H, 7.5. 
on the monomer unit) was small, the product (Polymer C) was soluble in the reaction mixture, but an insoluble product (Polymer D) was formed by increasing the ratio above 0.1 . When the ratio was 0.3 and above, PBVE was exclusively converted to Polymer D. The elementary analyses of the reaction products are listed in Table III.

Polymer D was white powder and decomposed gradually above $210^{\circ} \mathrm{C}$. It was insoluble in the usual organic solvents including benzene, toluene, cyclohexanone, and dimethyl sulfoxide. It was swollen in water and soluble in $1 N$ hydrochloric acid. Most of the insoluble products (Polymer D) showed no absorption band due to the benzyl group in their IR spectra and contained considerable amounts of chlorine and titanium as shown in Table III. When Polymer D was reprecipitated five times by pouring the solution in $1 N$ hydrochloric acid into methanol, the amounts of titanium decreased to about onefifth of the original. When reprecipitation was performed from the solution containing acetylacetone, titanium and chlorine in the polymer decreased to trace amounts, and the polymer became soluble in water. This water soluble product was proved to be PVA by elementary analysis and the infrared spectrum.

Polymer $\mathrm{C}$ which had been in solution in the reaction of $\mathrm{TiCl}_{4}$ and $\mathrm{PBVE}$, became insoluble when it was once precipitated in methanol. The precipitated product was insoluble in usual organic solvents such as benzene, toluene, and acetone, as well as in water and hydrochloric acid, and showed an infrared absorption due to the benzyl group. Polymer $\mathrm{C}$ also contained titanium and chlorine as shown in Table III. However, these were not removed by the treat- ment with acetylacetone in $1 N$ hydrochloric acid, probably because of the insolubility of the polymer.

The mixture of $n$-butyl benzyl ether and $\mathrm{TiCl}_{4}$ $(5: 1 \mathrm{~mol} / \mathrm{mol})$ was heated at $60^{\circ} \mathrm{C}$ for 2 hours. The product was distilled under reduced pressure, and the residual material was reprecipitated from the benzene solution by methanol and dried in vacuo. The results are summarized in Table IV, which shows that the ether was cleaved to benzyl chloride and $\mathrm{TiCl}(\mathrm{OBu})_{3}$ and a part of the former was polymerized to polybenzyl.

The observations described above suggested that the reaction product of $\mathrm{TiCl}_{4}$ and PBVE was a polymer formed by the partial or complete debenzylation of PBVE and complexed with a titanium compound. It may be composed of vinyl alcohol units and hydroxy titanium chloride with or without BVE units as follows

$$
\begin{aligned}
& \text { …- } \mathrm{CH}_{2}-\mathrm{CH}-\cdots+-\mathrm{CH}_{2}-\mathrm{CH}-\cdots \\
& \text { O } \mathrm{OH} \\
& \mathrm{CH}_{2} \quad \mathrm{TiCl}_{x}(\mathrm{OH})_{4-x} \\
& \mathrm{C}_{6} \mathrm{H}_{5}
\end{aligned}
$$

The compositions of the products were roughly estimated from the elementary analyses and are listed in Table III. When a small amount of $\mathrm{TiCl}_{4}$ was used, most of the product remained in solution with only a slight degree of debenzylation. The extent of debenzylation was increased by increasing the amount of $\mathrm{TiCl}_{4}$ used. As debenzylation reduces the molecular weight of the product, the amount of completely debenzylated product reached only a half of

\begin{tabular}{|c|c|c|c|c|c|c|}
\hline \multirow{2}{*}{ Product } & \multirow{2}{*}{$\underset{\left({ }^{\circ} \mathrm{C}(\mathrm{mm})\right)}{\mathrm{Bp}}$} & \multirow{2}{*}{$\underset{(\mathrm{g})}{\text { Yield }}$} & \multicolumn{3}{|c|}{ Elementary analysis $(\%)$} & \multirow{2}{*}{ Remarks } \\
\hline & & & $\mathrm{C}$ & $\mathrm{H}$ & $\overline{\mathrm{Ti}}$ & \\
\hline I & $65-66(13)$ & 3.8 & - & - & - & Benzyl chlorideb \\
\hline II & $130-135(3)$ & 4.8 & 48.5 & 8.9 & 15.0 & $\operatorname{TiCl}(\mathrm{OBu})_{3}{ }^{\mathrm{c}}$ \\
\hline III & Residue & 2.2 & 93.1 & 6.9 & - & $\left(\mathrm{C}_{6} \mathrm{H}_{4} \mathrm{CH}_{2}\right)_{n}^{\mathrm{d}}$ \\
\hline
\end{tabular}
the amount of the starting PBVE as shown in Figure 1.

Table IV. Reaction products of $n$-butyl benzyl ether and $\mathrm{TiCl}_{4}{ }^{\mathrm{a}}$

a $n$-Butyl benzyl ether, $0.1 \mathrm{~mol} ; \mathrm{TiCl}_{4}, 0.02 \mathrm{~mol}$; Temperature, $60^{\circ} \mathrm{C}$; Time, $2 \mathrm{hr}$.

b Identified from the infrared spectrum.

c Calcd for $\mathrm{C}_{12} \mathrm{H}_{27} \mathrm{O}_{3} \mathrm{TiCl}: \mathrm{C}, 47.6 ; \mathrm{H}, 9.0 ; \mathrm{Ti}, 15.8$.

d Calcd for $\left(\mathrm{C}_{7} \mathrm{H}_{6}\right)_{n}$ : C, 93.3; H, 6.7. Identified also by infrared spectroscopy using an authentic sample prepared by the reaction of benzyl chloride and $\mathrm{Et}_{2} \mathrm{AlCl}$. 


\section{DISCUSSION}

It was observed that the formation of insoluble polymer (Polymer B) from BVE by $\mathrm{Et}_{3} \mathrm{Al}-\mathrm{TiCl}_{4}$ is attained only in the case where the catalyst preparation and the monomer addition are done at low temperature and then the reaction mixture is brought to high temperature.

It is well known that the reaction products of equimolar amounts of $\mathrm{TiCl}_{4}$ and $\mathrm{Et}_{3} \mathrm{Al}$ are $\mathrm{TiCl}_{3}$ and $\mathrm{Et}_{2} \mathrm{AlCl}$ at high temperature. However, when the reaction is carried out at low temperature, partially unreacted $\mathrm{Et}_{3} \mathrm{Al}$ and $\mathrm{TiCl}_{4}$ may possibly remain in the reaction mixture. ${ }^{7}$ Such a catalyst system may rapidly cause the polymerization of BVE by cationic species such as $\mathrm{Et}_{2} \mathrm{AlCl}, \mathrm{TiCl}_{4}$ and/or $\mathrm{TiCl}_{3}$ to give a soluble polymer of this monomer. Among them $\mathrm{TiCl}_{4}$ gave an insoluble polymer above $0^{\circ} \mathrm{C}$ (Table II).

From these facts it seems to be clear that when insoluble polymer is formed by the action of a Ziegler catalyst, a part of the $\mathrm{TiCl}_{4}$ used remains unreacted and the PBVE formed is attacked by this $\mathrm{TiCl}_{4}$ at an elevated temperature.
The reaction of $\mathrm{TiCl}_{4}$ and $n$-butyl benzyl ether demonstrated that the $\mathrm{O}-\mathrm{CH}_{2} \mathrm{C}_{6} \mathrm{H}_{5}$ linkage of benzyl ether is easily cleaved by the $\mathrm{Ti}-\mathrm{Cl}$ compound to give benzyl chloride and titanium alkoxide. Stadnikoff ${ }^{8}$ has reported that diphenylmethane and dibenzylbenzene were obtained by the reaction of $\mathrm{TiCl}_{4}$ and ethyl benzyl ether in benzene. Nishizaki ${ }^{9}$ has obtained polybenzyl by the reaction of alkyl benzyl ether with $\mathrm{AlCl}_{3}$ or $\mathrm{ZnCl}_{2}$.

When $\mathrm{TiCl}_{4}$ attacks the $\mathrm{O}-\mathrm{CH}_{2} \mathrm{C}_{6} \mathrm{H}_{5}$ linkage in PBVE, it forms benzyl chlorides and $\mathrm{O}-\mathrm{Ti}$ bonds in the polymer. The completely debenzylated product of PBVE was formed at the molar ratio of $\mathrm{TiCl}_{4}$ to the polymer being above $1 / 3$, and approximately one chlorine atom remained per one titanium atom in the product (Table III). The reactivity of titanium chloride may be reduced by the substitution of the $\mathrm{Cl}$ atom with the alkoxy group, so that $(\mathrm{RO})_{3} \mathrm{TiCl}$ has little reactivity with the benzyl ether at the conditions employed in this work.

Consequently, the reaction of PBVE with $\mathrm{TiCl}_{4}$ may proceed as follows

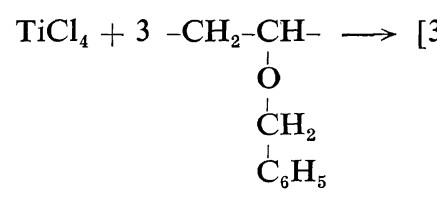

The elementary analyses (Table III) show that the products seem to be II, which is the hydro-

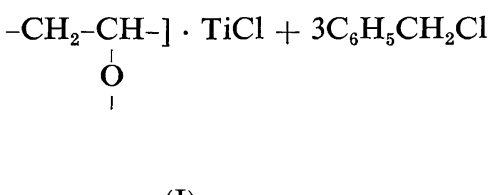

(I)

lyzate of I by water contained in methanol used as the precipitant. In the product II

$$
2 \mathrm{I} \stackrel{\mathrm{H}_{2} \mathrm{O}}{\longrightarrow}\left[6-\mathrm{CH}_{2}-\mathrm{CH}-\right] \cdot \mathrm{TiCl}(\mathrm{OH})_{3}+\mathrm{Ti} \text { compound }
$$

titanium may be coordinated with vinyl alcohol units in different polymer chains resulting in the cross-linking of the polymers. In the above reaction polybenzyl might be derived from benzyl chloride by $\mathrm{TiCl}_{4}$, but it was not obtained. Probably the low concentrations of these chlorides in the reaction mixture gave this polymer only in a quite small amount or with so low a molecular weight that the polymer could not be precipitated by methanol.

The following conclusions may be derived from the above considerations. The soluble polymer
(Polymer A) obtained by the $\mathrm{TiCl}_{4}-\mathrm{AlEt}_{3}$ catalyst is a low molecular weight PBVE which is similar to that obtained by the usual cationic polymerization at high temperature. The insoluble and elastic polymer (Polymer B) given by the same catalyst is a slightly debenzylated one cross-linked by a titanium compound. This is produced by a small concentration of $\mathrm{TiCl}_{4}$ and most of the benzyl groups remained in the chain. Such a polymer can be swollen in hot cyclohexanone and the titanium compound may be removed by chelation with the ketone giving a soluble poly- 
mer very similar to Polymer A. Polymer C, the product in the reactions of $\mathrm{PBVE}$ and $\mathrm{TiCl}_{4}$ at small concentrations of the latter, must be similar to Polymer B. Both Polymer B and Polymer C were soluble in the reaction mixtures. The extent of debenzylation, that is, the substitution of the benzyl group by the titanium compound, was so slight that the titanium alcoholate was not formed intermolecularly and the polymers were still soluble in the dilute solution. When the polymer is precipitated by methanol containing water, the alcoholate is hydrolyzed and the titanium will be coordinated with vinyl alcohol units in different polymer chains resulting in the cross-linking of the polymer. The increase in the concentration of $\mathrm{TiCl}_{4}$ by the reaction with PBVE decreases the amount of the benzyl group in the product and increases the extent of cross-linkage by titanium compounds as a result of the formation of intermolecular alcoholate of titanium. However, if the product retains a considerable amount of the benzyl group, it is not soluble in hydrochloric acid and cannot be attacked by acetylacetone in this acid. If the product has a lot of cross-linkage and only a trace of the benzyl group, it becomes very similar to crosslinked PVA and is insoluble in cyclohexanone even at high temperature.

The PVA cross-linked with hydroxy titanium chloride, the reaction product (Polymer D) of $\mathrm{TiCl}_{4}$ and PBVE, was cast as a film from its solution in hydrochloric acid. The film was rather rigid compared with that of the usual PVA, but showed only amorphous X-ray patterns. Beacham $^{10}$ reported that titanium tetraalkoxide is used as a cross-linking agent for PVA. We found that the cross-linked PVA can also be converted to PVA almost free from cross-linkage by reprecipitation from the solution in hydrochloric acid containing acetylacetone.

Acknowledgment. The authors wish to express their sincere thanks to Mr. Masakazu Okumiya for elementary analyses of the polymers and also to Mrs. F. Yano for clerical assistance in preparing the manuscript.

\section{REFERENCES}

1. J. La1, J. Polym. Sci., 31, 179 (1958); G. Natta, et al., Angew. Chem., 71, 205 (1959); H. Sobue and Y. Saito, Kogyo Kagaku Zasshi (J. Chem. Soc. Japan, Ind. Chem. Sect.), 64, 1321 (1961); A. B. Bogdanova, et al., Vysokomol. Soedin., 11, 576 (1960).

2. E. J. Vandenberg, J. Polym. Sci., 41, 519 (1959).

3. S. Murahashi, H. Yuki, T. Sano, U. Yonemura, H. Tadokora, and Y. Chatani, J. Polym. Sci., 62, S 77 (1962).

4. W. Reppe, et al., Ann., 601, 84 (1956).

5. E. M. Van Duzee and H. Adkins, J. Amer. Chem. Soc., 57, 147 (1935).

6. H. Yuki, K. Hatada, K. Ota, I. Kinoshita, S. Murahashi, K. Ono, and Y. Ito, J. Polym. Sci., Part A-1, 7, 1517 (1969).

7. H. Uelzmann, J. Polym. Sci., 37, 561 (1959).

8. G. Stadnikoff and L. Kaschtanoff, Ber., 61, 1389 (1928).

9. S. Nishizaki and Y. Kurusu, Nippon Kagaku Zasshi (J. Chem. Soc. Japan, Pure Chem. Sect.), 85, 504 (1964).

10. H. H. Beacham, "Metal-Organic Compounds,", Advances in Chemistry Series, American Chemical Society, Washington, D. C., 1959, p. 284. 